\title{
The Relationship among Fashion Social Media, Information Usage Behavior, and Purchase Intention*
}

\author{
패션 소셜미디어 품질, 정보 이용행동, 구매의도 간 관계 연구 \\ Naeeun $\operatorname{Kim}(\text { 김내은 })^{* *}, \mathrm{Mi}-\mathrm{Sook} \operatorname{Kim}(\text { 김미숙 })^{* * *}$ \\ Received: October 15, 2018. Revised: October 30, 2018. Accepted: November 10, 2018.
}

\section{Abstract}

Purpose - This study aimed to identify the sub-dimensions of fashion social media quality (information quality, social quality, service quality, system quality) and investigate how they affect purchase intention through fashion information use behavior (information acceptance, information diffusion).

Research design, data, and methodology - Data collection was carried out twice for systematic verification of the research model. In the first data collection, the reliability and validity of research variables were verified through 238 respondents and questionnaires were revised and supplemented based on their responses. In March 2018, the final survey was conducted from 755 respondents the age of 20 to 49. Using SPSS 23.0, descriptive statistics, exploratory factor analysis, correlation analysis were performed. In order to test hypotheses, structural equational modeling technique was employed using AMOS 23.0.

Results - First of all, fashion Social media quality consists of four factors including information quality, social quality , service quality and system quality. Second, fashion Social media information quality, social quality, and system quality were shown to have a positive $(+)$ effect on information acceptance behavior, and social quality, service quality and system quality were shown to have a positive $(+)$ effect on information diffusion behavior. It was also determined that the acceptance and diffusion behaviors of fashion information through fashion Social media had positive $(+)$ influence on purchase intention.

Conclusions - This study holds academic significance in its identification of the components of fashion Social media quality and for conducting an empirical analysis on the causal relationship between fashion information acceptance and diffusion behaviors, and purchase intention. The results of this study indicate that fashion involvement is the key factors in determining the quality of Social media, the acceptance of information through Social media, and, by extension, the purchase of fashion products. Practitioners in the fashion industry may use the findings of this study in order to build more effective Social media strategy.

Keywords: Fashion Social Media Quality, Information Usage Behavior, Purchase Intension.

JEL Classifications: D91, L82, M31.

\section{1. 서론}

개인 간 개인이 정보를 소통하는 플랫폼으로 등장한 소셜미 디어는 ICT 기술의 발전과 모바일 기기의 확산 등으로 현대인

* This paper was modified and developed from the Ph.D. thesis of the first author.

** First Author, Department of Clothing \& Textiles, Kyung Hee University, Korea.

*** Corresponding Author, Department of Clothing \& Textiles, Kyung Hee University, Korea.

Tel: +82-2-961-0772, E-mail: mskim@khu.ac.kr
의 삶 속에서 주요한 표현, 공유의 수단으로 활용되고 있다. 이처럼 소셜미디어를 활용하는 방법과 사람이 많아지면서 미 디어로서의 영향력이 개인과 기업에게 미치고 있다(Choi, 2017; Seo, 2016). 개인에게는 정보를 탐색하고 활용하는 방 법, 소비방식의 변화를 가져왔고, 기업에게는 소비자와의 커뮤 니케이션 방법, 마케팅 방법의 변화를 가져왔다. 소셜미디어는 소통, 관계의 도구를 기반으로 쉽고 효율적인 마케팅을 위해 활용되고 제품의 판매로까지 연결되고 있다. 이는 매스미디어 의 높은 마케팅 비용을 부담하지 않고도 마케팅이 가능한 환 경이 됨에 따라 다양한 기회를 만들어 주고 있다(Chae, 2018). 소셜미디어의 사용자는 1 인 미디어로서 경제활동의 주체자 가 되었고, 사회적 영향력도 커졌다(Seo, 2016). 즉, 독립적이 
고 능동적인 프로슈머인 것이다(Choi, 2016). 이는 개개인의 영향력이 커질 수 있는 가능성을 의미하기도 한다(Park, 2018). 사용자들은 소셜미디어를 통해 정보를 탐색, 공유, 생 산하며, 관계를 새롭게 형성하고 이를 일상적으로 활용한다 (Shin, 2017). 이는 라이프스타일와 패러다임의 변화를 야기하 기도 한다(Jang, 2018). 소셜미디어의 활용이 많아지면서 사용 자들의 기대와 욕구가 함께 높아지고 있다. 이러한 기대와 변 화와 더불어 정보의 홍수 속에서 주요한 정보원이 되면서 소 셜미디어의 콘텐츠에 대한 사용자의 욕구와 기대가 높아지고 있다(Mun, 2016).

기업 역시 이러한 변화에 적극적으로 대응하고자 소비자와 의 소통 방법, 마케팅, 판매, 홍보의 도구로 소셜미디어를 활 용하는 방법을 고민하며 시도하고 있다. 패션산업에서도 패션 인플루언서(influencer)의 영향력에 주목하고 있다(Kim, 2018). 패션 기업은 소셜미디어를 통해 고객과 소통하고 관계를 형성 하기 위해 다양한 노력을 하고 있다(Park, 2018). 패션 소셜미 디어의 해시태그 '\#SeeNowBuyNow'는 변화의 지표이다. 소셜 미디어의 실시간 빠른 정보의 공유로 인해 소비자들은 원하는 제품을 즉시 구입하고자 하는 니즈가 생겨났고, 패션기업의 제 품 출시 방식의 변화를 가져왔다(Yu, 2016). 즉, 소셜미디어 세대의 욕구를 충족시켜 공략하고자 적절한 전략을 수립하는 것이다(Mun, 2016).

소셜미디어를 활용하는 소비자가 소셜미디어를 사용함에 있 어서 중요하게 인식, 지각하는 것에 대한 파악은 욕구와 기대 를 충족하기 위해 필수적이라고 할 수 있다(Ahn, 2013). 이로 인해 소셜미디어 활용에서 중요하게 지각하는 가치를 밝히는 품질에 대한 연구에 대한 관심이 높아지고 있다.

소셜미디어 품질에 대한 선행연구는 소셜미디어 품질과 만 족, 이용 및 행동의도의 영향관계, 소셜미디어 품질이 이미지 에 미치는 영향, 품질에 대한 인식 연구 등으로 대부분 전반적 인 소셜미디어를 다루거나, 공공기관, 선매서비스, 관광, 호텔 경영분야에서의 연구들이다(Cho, 2014; Choi, 2017; Hur, 2016; Kim, 2015; Kim, 2017; Ko, 2012; Lee, 2014; Lee, 2016; Shin \& Ji, 2014; YanShu, 2016).

패션산업분야의 소셜미디어에 관한 연구는 공급자 관점에서 마케팅 도구로서의 연구와 패션 소비자 관점에서의 소셜미디 어 활용에 대한 연구가 있다. 구체적으로 살펴보면, 패션브랜 드 커뮤니티 소셜미디어 참여행동과 광고효과 연구(Lee \& Lee, 2011), 패션 블로그를 중심으로 소셜미디어에 등장하는 패션 스타일 분석(Suh \& Kim, 2014), 소셜미디어에서의 패션 콘텐츠 생산 활동( $\mathrm{Im}, 2015)$, 페이스북 이용동기, 상호작용성 과 패션 제품 구전, 구매의도의 영향관계 연구(Park, 2014) 등 으로 소비자 관점의 소셜미디어 품질과 관련된 연구는 미흡한 실정이다.

패션 기반 소셜미디어의 지각된 품질과 정보이용행동, 구매 의도의 인과관계에 대해 구체적으로 구성된 모형을 보여준 연 구는 현재까지 다루어지지 않았다. 이에 본 연구는 패션 소셜 미디어를 이용하는 패션 소비자가 지각하는 패션 소셜미디어 품질 구성요인을 밝히고, 패션 소셜미디어 품질이 패션정보 이 용행동인 정보수용과 확산, 구매의도에 미치는 관계를 구조적 으로 규명하고자 하였다. 본 연구를 통해 패션 소셜미디어를 활용하는 소비자 행동 연구에 기초자료를 제공하고, 패션 소셜 미디어를 통해 패션 정보의 수용, 확산활동과 구매의도를 일으 키기 위한 패션 소셜미디어 품질 전략수립에 도움이 되는 구 체적인 방안을 제시하고자 하였다.

\section{2. 이론적 배경}

\section{1. 소셜미디어 품질}

소셜미디어의 품질은 매체적 품질과 기능적 품질로 나눌 수 있다(Shin \& Ji, 2014). 매체적 품질은 사회심리학적 측면으로 소셜미디어가 이용이 자유롭고, 이용자들 간 정보 및 경험을 공유하며, 양방향 인터렉션이 가능한 커뮤니케이션 도구이기 때문에(Kozinets, Valck, Wojnicki, \& Wilner, 2010), 사회성 품 질, 감성 품질, 서비스 품질이 정보시스템의 연구에서 확장 모 델로 다루어지고 있다(Shin \& Ji, 2014). 기능적 품질은 정보 공학적 측면으로 사용의 용이성이나 정확하고 신뢰할 수 있는 정보에 대한 품질로 정보 품질, 시스템 품질, 인터페이스 품질 이 있다(Kim, Sung, \& Jeong, 2007).

정보시스템 품질에 관한 연구에서 웹사이트 품질이 주로 연 구되었고, 대표적으로 DeLone and McLean(1992)의 정보시스 템 성공 모델(IS success model)이 있다. DeLone and McLean(1992)은 많은 논문 분석을 통해 정보시스템 성공을 위한 구성요소로 정보품질, 시스템품질, 사용, 만족, 개인성과, 조직성과로 구성하였다. 정보품질은 정확성, 의미감, 적시성의 정보 생산에 관련된 것으로 보았고, 시스템품질은 정보를 생산 하는 정보시스템 그 자체의 특징으로 정의하였다. 정보시스템 사용과 만족은 정보와 정보 수용자의 상호작용으로 의미하였 고, 이러한 구성 요인을 바탕으로 정보 시스템 성공 모형을 제 시하였다. 여러 연구자에 의해 정보시스템 성공모형은 모델이 검증, 변형, 확장되었다. Pitt, Watson, and Kavan(1995)은 정 보시스템 성공모형의 품질 구성요인으로 정보 품질, 시스템 품 질과 더불어 서비스 품질을 포함해야 한다고 주장하였다.

최근 연구에서 구성된 품질 요인을 살펴보면, Shin and $\mathrm{Ji}(2014)$ 는 콘텐츠 품질, 인터페이스 품질, 서비스 품질, 감성 품질로 소셜미디어 품질을 구성하였다. 콘텐츠 품질은 최신의 콘텐츠 제공, 콘텐츠 내용의 흥미로움, 콘텐츠 내용이 다양하 고 풍부함, 콘텐츠 내용이 간결하고 명료함, 콘텐츠 내용이 조 직적, 체계적임 등으로 구성되어 측정되었다. 인터페이스 품질 은 PC, 모바일, 웹브라우저에서의 이용 지원, 소셜미디어에서 링크, 라벨, 사이트 맵 제공, 콘텐츠와 인터페이스의 설정, 웹 사이트에 도달하는 시간으로 측정되었다. 서비스 품질은 신속 한 서비스 제공, 고객 요구에 신속한 반응, 운영시스템 신뢰 등으로 측정되었다. 감성 품질은 상호작용과 지식 공유의 지원 정도, 사용자를 즐겁게 만듦, 정신적 몰입으로 구성되어 측정 되었다. Lee(2014)는 경찰청 소셜미디어 품질을 위해 정보 품 질 구성요인을 이해용이성, 정확성 최신성으로, 시스템 품질 구성요인을 접근성, 이용용이성, 안정성으로, 서비스 품질 구 성요인을 공감, 반응, 확신으로 구성하였다. Cho and $\mathrm{Kim}$ (2014)는 정보품질, 사회적품질, 서비스품질로 구성하였다. Hur (2016)는 소셜미디어의 정보제공자가 전달하는 정보의 객관적 인 품질과 소셜미디어의 정보를 제공하는 정보제공자에 대한 신뢰로 정교화 가능성 모형을 바탕으로 한 품질을 구성하였다. YanShu(2016)는 정보 품질 구성요인을 정확성, 유용성, 적시 성, 완전성, 이해가능성으로, 시스템 품질 구성요인을 기능성, 안정성, 보안성으로, 서비스 품질 구성요인을 유형성, 신뢰도, 반응성, 공감성, 확신성으로 한 소셜미디어 품질을 구성하였다. 최근의 연구를 살펴보면, 인터페이스 품질에 대한 연구가 줄어 들고 있는 것을 알 수 있다. 또한 인터페이스 품질을 구성한 연구 결과를 살펴보면, Shin and Ji(2014)는 인터페이스 품질 
만 사용자 만족에 유의한 영향을 미치지 않는 것으로 분석하 였고, Lee and $\mathrm{Kim}(2013)$ 은 인터페이스 품질을 중요도는 낮 고, 만족도가 높은 영역을 의미하는 과잉영역이라고 분석하여, 중요한 품질속성이 아니라고 주장하였다. 이외에도 $\mathrm{Kim}$ and Hwang(2012), Ahn and Han(2011), Suh, Won, and Hong (2010)의 연구에서도 인터페이스 품질은 만족, 재방문의도, 구 매의도 등에 유의한 영향을 미치는 요인이 아니라는 결과가 나왔다. 따라서 본 연구에서는 인터페이스 품질은 소셜미디어 품질요인 구성에서 제외하였다.

소셜미디어의 특성 중 대표적인 상호작용에 대한 품질을 어 떻게 지각하고 있는지 파악할 수 있는 것이 사회성품질이다. 그러나 사회성품질을 포함시킨 연구는 활발하게 이루어지고 있지 않은 실정이다. 사회성품질을 연구한 Cho and $\mathrm{Kim}$ (2014)는 정보품질과 서비스품질보다 사회적품질이 구매의도 나 추천의도로 측정한 행동적 태도에 가장 큰 영향을 미치는 품질요인인 것으로 분석하였다. Ko, Kim, Jung, Oh, and Lee (2011)도 사회성품질이 SNS 사용의 만족과 지속적 이용의도 에 유의한 영향을 주는 품질 요인임을 밝혔다. 따라서 사회성 품질을 본 연구의 품질요인으로 구성하였다.

이에 본 연구에서는 DeLone and McLean(2003)의 정보시 스템 성공 모형에서 구성된 품질 요인인 정보품질, 시스템품 질, 서비스품질과 소셜미디어의 상호작용성과 관련된 사회성품 질을 추가하여 구성하였다.

\section{2. 정보 이용행동}

소셜미디어를 통한 정보 이용행동은 소극적 행동과 적극적 행동으로 나눌 수 있다. 정보를 읽기만 하는 것은 소극적인 정 보 소비행동이고, 의견을 만들어 다른 사람에게 영향을 미치는 것은 적극적인 행동이다(Rha, 2010). Shin(2016)은 정보 이용 행동을 3단계로 나누었다. 정보 탐색하고, 검색하는 가장 소극 적 정보소비 단계의 활동인 정보 획득활동, 타인에게 지식이나 정보를 공유하는 단계의 활동으로 정보 확산활동, 사용자가 새 로운 자료와 정보를 생성하여 업로드하는 적극적인 단계의 활 동인 정보 생산활동, 이렇게 3단계의 행동으로 구분하였다. $\mathrm{SeO}(2015)$ 는 적극적으로 의견을 게재하거나 정보 공유 행동인 확산활동과 정보나 의견을 수용하는 소극적인 행동인 수용활 동으로 미디어 이용행위를 구분지었다. Rha(2010)는 SNS에서 정보 이용행동을 검색, 읽기, 보기 등의 정보 획득과 댓글 달 기, 퍼나르기와 변형 등의 정보 확산으로 정의하였다. 이처럼 사용자는 소셜미디어를 통해 정보를 얻고, 정보를 나누며, 다 른 사람에게 공유하는 등의 이용행동을 한다(Shin, 2017).

패션 정보 탐색, 활용을 위한 소셜미디어 이용행동 또한 하 나의 행동으로 보지 않고, 세분화하여 살펴볼 필요가 있다. 기 존 연구에서는 대체로 소셜미디어의 이용자 집단을 단일 집단 으로 정의하여 연구하였지만, 이는 한계가 있다고 지적하는 학 자들이 많다(Kim, Shin, Im, \& Lee, 2013; Shin, 2016). 따라서 관찰자 시점으로 정보를 단순하게 수용하는 이용행위, 수용하 는 활동에서 더 나아가 정보의 생산자로 적극적인 메시지를 만들어 내는 이용행위를 나누어 연구할 필요성이 제기되었고, 진행되고 있다(Kim \& Lee, 2011; Shin, 2016).

\section{3. 구매의도}

구매의도란 소비자의 계획되거나 예상되는 미래 구매행동에
대한 의도로 이에 대한 태도, 신념이 행동으로 옮겨질 가능성 이라고 정의할 수 있다(Engel, Blackwell, \& Paul, 1994; Fishbein \& Ajzen, 1975). 온라인상에서의 구매의도는 웹사이 트를 통하여 이용자가 상품구매에 대한 가능성 정도를 의미한 다(Poddar, Donthu, \& Wei, 2009). Hoffman and Novak(1996) 은 온라인에서의 구매의도를 측정함에 있어서는 재방문의도와 같은 충성도 있는 행위를 측정해야 한다고 주장하였다. 구매의 도는 향후 구매에 대한 의향이나 가능성, 타인에게 추천하려는 의도 등으로 측정이 가능하고, 구매행동을 예측하기에 신뢰할 수 있는 변수이다(Kalwani \& Silk, 1982). 따라서 마케팅 분야 의 연구에서 구매에 직접적인 영향을 미치는 결정요인으로 빈 번하게 사용되고 있다(Ahn \& Lee, 2002).

정보시스템 중 온라인 쇼핑과 관련된 분야에서 행동의도는 구매의도나 재구매의도로 측정되었다(Bae, 2013; Hausman \& Siekpe, 2009; Siekpe, 2005). 행동의도는 특정 대상에 대해 사용자가 태도를 형성하고, 사용의도와 추천의도 등 향후 어떠 한 행동을 하려는 사용자의 동기, 신념과 의지를 말하고 (Boulding, Kalra, Staelin, \& Zeithaml, 1993; Lee \& Park, 2005; Madden, Ellen, \& Ajzen, 1992; Sommer, 2011), 구전, 추천, 지속적 이용과 우선적인 선택 등으로 측정하였다(Boulding et al., 1993; Zeithaml, Berry, \& Parasuraman, 1996).

Sung and $\mathrm{Ko}(2013)$ 는 SNS를 통해 정보를 검색하는 외식 소비자에 대한 연구에서 행동의도를 지속적 이용의도로 파악 하였다. Cho and Lee(2014)는 모바일 커머스 연구에서 지속 적인 구매의도, 검색의도와 추천의도로 측정하였다. 또한 Lee and Nam(2015)은 외식소비자의 업체 SNS이용이 구매결정에 도움이 되는 정도, 향후 해당 업체 이용 가능성 정도, 주변사 람들에게 구전 정도 등의 항목으로 구매의도를 측정하였다.

\section{3. 연구모형 및 가설}

\section{1. 연구모형}

본 연구는 패션기반 소셜미디어를 통해 패션정보를 탐색, 활용하는 패션소비자 행동에 대한 통합적 연구로서 선행 연구 를 토대로 패션 소셜미디어 품질이 패션정보 이용행동, 구매의 도에 미치는 인과관계에 대하여 <Figure 1>과 같이 연구모형 을 설정하였다.

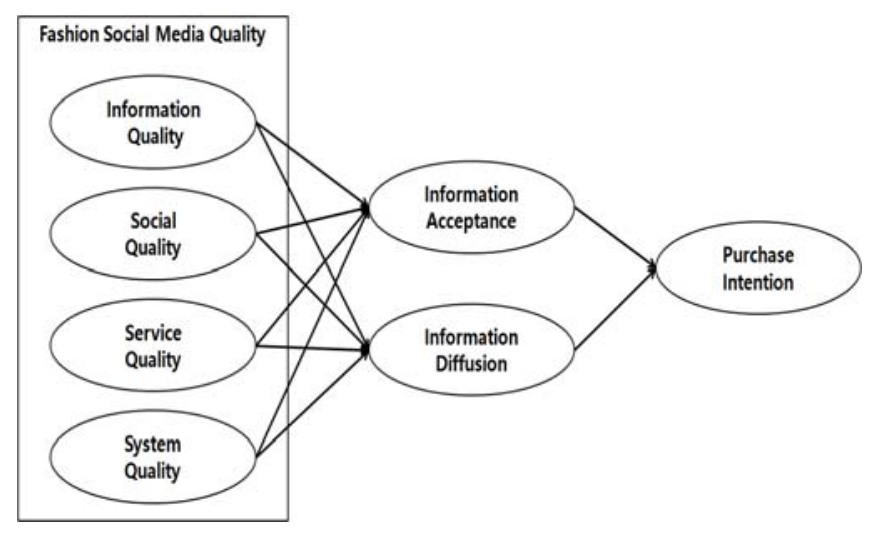

Figure 1: Research Model 


\section{2. 연구가설}

소셜미디어와 같은 정보시스템에서 품질요인은 중요하게 연 구되어 왔다. 왜냐하면 소셜미디어 품질은 소셜미디어를 이용 하는 사람들이 소셜미디어에 대해 어떠한 가치를 중요하게 지 각하는지를 보여주기 때문이다. 최근 패션 정보나 브랜드 정보 에 대한 정보원이 소셜미디어로 주도권이 이동한 상황에서 패션 기반 소셜미디어의 품질에 대한 연구는 중요하다고 할 만하다.

정보시스템 성공모델 초기에는 정보시스템의 기술적 측면인 정보품질과 시스템품질이 정보시스템 사용(웹사이트 방문, 탐 색, 정보검색, 트랜잭션) 또는 사용자 만족에 영향을 미치는 것으로 나타났다(DeLone \& McLean, 1992; Seddon \& Kiew, 1994; Seddon, 1997). 기술적 측면의 특성은 사용자에게 최적 화된 온라인 환경을 제공하는데 있어 중요한 역할을 하고 (Hyun, Kim, Nam, \& Kim, 2014), 소셜미디어 사용자가 정보 를 탐색, 공유하는 시간과 노력을 줄일 수 있도록 해줄 뿐 아 니라 정보 탐색 활동에 몰입하게 한다(Gao, Bai, \& Park, 2014). 이후 연구자들은 서비스품질을 추가 구성하여 정보시 스템 사용 또는 만족을 측정하여야 한다고 주장하였다(DeLone \& McLean, 2003; Pitt, Watson, \& Kavan, 1995; Prybutok, Kappelnan, \& Myers, 1997).

웹사이트 품질요인의 평가요소가 기초가 되어 소셜미디어 품질 역시 서비스품질이 포함된 정보시스템 성공모델을 기반 으로 검증하는 연구가 활발히 진행되었다. 개선된 정보시스템 성공 모형에서 특정 시스템은 정보, 시스템, 서비스 품질에 대 해 평가되어지고, 이 품질 특성은 사용, 사용의도와 사용자의 만족감에 영향을 준다는 것이다. 또한 사용의 결과로서, 어떠 한 이익이 얻어지면 그것이 긍정적이든 부정적이든 순이익은 정보시스템 이용에 영향을 미친다고 나타내고 있다. hur(2016) 은 소셜미디어를 통해 여행 정보를 탐색하는 이용자를 대상으 로 한 정보품질과 소셜미디어 정보 제공자에 대한 신뢰, 정보 공유의도 등의 영향관계 연구에서 정보품질은 정보의 일관성, 정보의 적절함, 정보의 정확함으로 구성하였고, 소셜미디어에 서 제공하는 정보의 신뢰와 정보 제공자에 대한 신뢰 등으로 측정한 정보원의 신뢰에 정(+)의 영향을 나타냈다. 정보 제공 자에 대한 신뢰는 서비스품질과 유사한 의미로 해석할 수 있 고, 정보 제공자에 대한 신뢰는 정보 공유의도에 정(+)의 영향 을 미친다고 하였다. Petty and Cacioppo(1996)는 설득적인 커뮤니케이션에서 정보원의 신뢰는 정보의 수용과 같은 중개과정 을 통해서 태도 변화를 이끌어 낸다고 하였다. 따라서 본 연구는 DeLone and McLean(2003)의 정보시스템 성공 모형(IS Success model)에서 품질 특성이 사용에 영향을 미친다는 모형을 토대로 하였고, 소셜미디어 사용에 대한 선행 연구를 바탕으로 사용을 정보수용으로 하여 다음과 같은 가설 1 을 설정하였다.

$\mathrm{H} 1$ 1: 정보품질은 정보수용에 정(+)의 영향을 미칠 것이다. $\mathrm{H} 1$ 2: 사회성품질은 정보수용에 정(+)의 영향을 미칠 것이다. $\mathrm{H} 1$ 3: 서비스품질은 정보수용에 정(+)의 영향을 미칠 것이다. $\mathrm{H} 1$ 4: 시스템품질은 정보수용에 정(+)의 영향을 미칠 것이다.

가설 2는 품질요인 중 경제성과 정확성, 유희적 경험 가치, 심미적 경험 가치가 확산 의도에 유의한 영향을 미쳤다고 분 석한 Lee(2017)의 연구와 DeLone and McLean(2003)의 품질 요인이 사용에 영향을 미친다는 결과를 바탕으로 사용을 정보
확산으로 보고 다음과 같은 가설 2를 설정하였다.

$\mathrm{H} 2$ _1: 정보품질은 정보확산에 정(+)의 영향을 미칠 것이다. $\mathrm{H} 2$ 2: 사회성품질은 정보확산에 정(+)의 영향을 미칠 것이다. $\mathrm{H} 2$ 3: 서비스품질은 정보확산에 정(+)의 영향을 미칠 것이다. $\mathrm{H} 2 \_4$ : 시스템품질은 정보확산에 정(+)의 영향을 미칠 것이다.

패션 기반 소셜미디어의 패션정보 이용행동은 이용자가 정 보를 발견, 탐색 등의 행위와 다른 사람들에게 지식 및 정보를 공유하는 행위로 나눌 수 있다(Kong \& Sung, 2014; Park, 2006; Rha, 2010; Shin, 2016). 사용자들은 소셜미디어에서 다 양한 마케팅 커뮤니케이션 콘텐츠와 제품, 서비스에 대한 사람 들의 게시물을 접하고, 관심 있는 제품 혹은 서비스는 직접 검 색하여 정보를 탐색하고, 콘텐츠를 이용한다(Cho \& Cheon, 2005). 정보 탐색활동의 수준이 높을수록 정보와 사용자의 상 호작용이 활발하게 이루어진다는 것을 의미한다(Cho \& Leckenby, 1999; Kim \& Joo, 2001; Park, 2014).

Lee and Nam(2015)은 SNS 품질과 만족도, 이용의도, 구매의 도의 인과관계에서 SNS를 지속적으로 이용하려는 의향은 SNS를 활용한 구매의도와 추천의향에 유의한 영향을 미친다고 하였다.

정보의 수용이라 여길 수 있는 구전 효과모델은 의도, 행동 의 선행 변수로 연구되었다. Lee(2004)은 구전 정보의 수용과 구매의도는 매우 밀접하다고 주장하였고, 온라인상의 구전정보 가 잠재소비자들의 구매의도를 촉진한다고 밝혔다(Chatterjee, 2001; Park \& Lee, 2014). Park(2014)에 따르면 SNS내 사용 자가 정보를 탐색하면서 일어나는 상호작용은 구매의도에 유 의한 영향을 미친다고 밝혔다. Jang(2014)은 소셜미디어의 구 전 정보의 수용은 구매의도에 정(+)의 영향을 미친다고 분석하 였다. DeLone and McLean(2003)의 정보시스템 성공 모형에 서도 시스템 사용은 긍정적, 부정적 이익을 경험하게 하는데, 개인적인 이익이 포함된 순이익은 사용의도와 사용에 영향을 미친다고 하였다. 따라서 본 연구는 선행연구를 바탕으로 다음 과 같은 가설 3 을 설정하였다.

H3_1: 정보수용은 구매의도에 정(+)의 영향을 미칠 것이다.

H3_2: 정보확산은 구매의도에 정(+)의 영향을 미칠 것이다.

\section{3. 측정변수의 조작적 정의와 측정}

패션기반 소셜미디어는 온라인을 통하여 다른 사람들과 패 션 관련 분야를 소통하는 온라인 미디어 서비스로 패션과 관 련된 주제를 바탕으로 소통하는 패션 브랜드나 패션관련 정보 를 제공하는 정보원이 운영하는 소셜미디어로 정의하였고, 패 션 소셜미디어 품질은 패션 정보 기반 소셜미디어를 통해 패 션과 관련된 정보를 탐색, 활용하는 패션소비자가 지각하는 품 질이라고 정의하였다. 본 연구에서는 패션 기반 소셜미디어 품 질의 구성을 정보품질, 사회성품질, 서비스품질, 시스템품질로 하여 각 품질에 대해 얼마나 가치 있게 지각하는 가를 측정하 였다. 정보품질은 소셜미디어에서 제공하는 정보의 특성과 수 준(Shin \& Ji, 2014)으로 정보시스템에 의해 만들어지는 산출 물의 품질을 의미하며(DeLone \& McLean, 1992), 정보에 대해 얼마만큼 가치 있게 지각하는가를 나타낸다(YanShu, 2016). 따라서 본 연구에서는 정보 품질을 소셜미디어를 통해 패션정 보를 검색하는 패션소비자가 정보에 대한 품질을 인지하고 지 
각하는 것으로서 '패션기반 소셜미디어를 통해 제공받는 패션 정보의 특성을 지각하는 정도'로 정의하였다.

패션관련 주제를 소통하는 소셜미디어의 품질은 일반적인 소셜미디어 품질보다 좀 더 시각적인 품질이 중요하다고 판단 되어 정보품질에서 시각적인 정보품질을 포함시켰다(Choi, 2017). 패션기반 소셜미디어 정보품질은 최신정보제공정도, 흥 미로움, 다양함, 풍부함, 유용함, 이해용이함으로 구성하였다. 여기에 패션 기반 소셜미디어에서 시각적인 정보 품질에 대한 평가로 미적매력, 감각적임, 예술적임을 구성하였다.

사회성품질은 주관적 규범, 사회 정체성의 형성과 이미지 요인, 이타주의에 대해 중요하게 지각하는 정도이다(Ko et al., 2011). 소셜미디어 이용이 주어진 관계에게 자신이 좋은 이미 지를 형성, 유지하면서 소속감을 느끼게 하고, 다른 이용자를 도울 수 있는 정도를 의미한다. 본 연구에서는 패션 소셜미디 어 사회성 품질을 '패션기반 소셜미디어에서 형성된 관계 속에 서 서로간의 행위에 의해 영향을 주고받는 정도'로 정의하였 고, 패션 소셜미디어 사용 시, 개인이 사회적 집단에 속하였다 는 소속감과 패션 소셜미디어 사용으로 준거집단 내에서의 긍 정적인 이미지 형성, 다른 사용자에게 도움을 주는 이타주의, 새로운 관계 형성, 교류 가능성 정도를 나타내는 문항 등 6 문 항으로 구성하였다.

서비스품질은 소셜미디어가 제공하는 서비스 활동이 사용자 의 요구를 얼마나 충족시켜 주는가를 의미한다(Lee, 2014). 서 비스품질은 사회심리가 반영된 인간적 측면의 품질이라고 할 수 있다(Kettinger \& Lee, 1997; Pitt et al., 1995; Van Dyke, Kappelman, \& Prybutok, 1997). 이에 본 연구는 서비스품질을 ‘패션기반 소셜미디어에서 패션관련 정보제공자가 정보 이용자 의 욕구를 충족시킬 수 있는 능력과 관련된 서비스의 정도'로 정의하였고, Parasuraman, Zeithaml, and Berry(1988) 등의 연 구를 바탕으로 패션 소셜미디어에 맞게 수정하

여 패션관련 정보제공자의 다양한 서비스 제공, 패션관련 정보제공자에 대한 신뢰, 패션관련 정보제공자의 지식과 능력, 요청에 대한 신속한 대처, 개인화된 서비스 등의 5 문항으로 구성하였다.

시스템품질은 정보시스템이 운영되는 그 자체의 품질(Gorla, Somers, \& Wong, 2010)이고, 데이터를 전달하는 시스템 성능 을 말한다(DeLone \& McLean, 1992). 시스템품질은 사용자들 의 정보 탐색, 공유에 필요한 시간과 노력을 줄이도록 도와주
고, 정보 탐색 행동에 몰입하게 한다(Gao et al., 2014). 본 연 구에서는 '패션기반 소셜미디어를 편리하고 쉽게 이용할 수 있 는지를 지각하는 정도'로 정의하였다. 게시물을 올리기 쉬운 정도, 콘텐츠 접근이 편리한 정도, 이용하기 편한 정도, 보완, 기능의 우수성 등의 5 문항으로 구성하였다.

온라인 이용 행동 중 다른 사용자가 게시한 콘텐츠를 보기 만 하고, 글을 남기는 등의 피드백을 주지 않는 소극적, 수동 적인 행동을 러킹(lurking)이라고 하며, 정보수용이라고 할 수 있다(Burnett, 2000). Rha(2010)는 이용자의 온라인 소셜 네트 워크의 활용 행동을 정보의 획득, 정보의 확산, 정보의 생산 3 가지로 구분하였고, 정보의 획득은 검색과 게시물, 동영상 보 기를 포함하며, 이러한 행동은 가장 낮은 수준의 활동으로 소 극적 행동을 의미하였다. 따라서 본 연구에서 정보수용은 '패 션기반 소셜미디어에서 패션 정보에 대한 소극적인 정보 탐색 행동'이라고 정의하였다. Shin(2016)과 Rha(2010)의 연구를 바 탕으로 ‘타인이 업로드한 패션관련 정보를 읽는다.', ‘타인이 업 로드한 패션 관련 사진을 본다.', '패션 관련 사람이나 게시물 을 검색한다.', '패션 관련 게시물, 댓글을 보고 영향을 받는다.' 의 5 문항으로 구성하였다.

정보확산에 대해 Shin(2016)은 다른 사람들에게 지식 및 정 보를 공유하는 행위라고 정의하였고, 이용 행위 중 수용보다 적극적인 행위라고 하였으며, 그 다음 단계인 정보 생산으로 자연스럽게 연결된다고 하였다(Rha, 2010). 따라서 본 연구에 서 확산을 정보 제공을 포함한 확산으로 확장적으로 해석하여 '패션기반 소셜미디어의 정보를 공유하여 다른 사람에게 영향 을 주는 이용행동'이라고 정의하였다. Shin(2016)과 Rha(2010) 의 연구를 바탕으로 '타인이 업로드 한 패션 관련 게시물에 댓 글을 단다.', '패션관련 게시물에 “좋아요”를 누른다.', '타인의 패션관련 게시물을 공유한다.', '패션관련 글을 작성하여 게시 한다.', '패션 관련 사진을 게시한다.', '패션관련 제품 구매 후 관련 정보를 공유한다.', '패션 관련 나의 경험을 올린다.'의 7 문항으로 구성하였다. 구매의도는 '패션기반 소셜미디어 정보 를 활용하여 패션제품을 구매하거나 패션정보를 추천할 의향' 으로 정의하였으며, 이를 알아보고자 Aaker(1991), Kim and Shin(2014)의 연구를 바탕으로 수정 보완하여 '소셜미디어의 패션정보를 활용하여 패션 제품을 구매할 의향', ‘패션 소셜미 디어를 통해 정보를 얻은 패션 제품에 대한 추천의향', '게시물 을 보고난 후 제품 구매경향' 등 총 4문항으로 구성하였다.

Table 1: Operational definition of variables

\begin{tabular}{|c|c|c|}
\hline variable & operational definition & preceding study \\
\hline Information Quality & $\begin{array}{l}\text { Perception of the characteristics of fashion information provided through } \\
\text { fashion-based social media }\end{array}$ & $\begin{array}{l}\text { DeLone \& McLean(1992), } \\
\text { Lee(2014), Hur(2014) }\end{array}$ \\
\hline Social Quality & $\begin{array}{l}\text { The degree to which people are influenced by each other's behavior in } \\
\text { the relationship formed in fashion-based social media }\end{array}$ & Ko(2012), Cho \& Kim(2014) \\
\hline Service Quality & $\begin{array}{l}\text { The extent of the services related to the ability of fashion-related } \\
\text { information providers to meet the needs of information users in } \\
\text { fashion-based social media }\end{array}$ & $\begin{array}{c}\text { DeLone \& McLean(2003), Parasuraman, } \\
\text { Zeithaml, \& Berry(1988) }\end{array}$ \\
\hline System Quality & Perceived ease of use of fashion-based social media & $\begin{array}{l}\text { DeLone \& McLean(2003), } \\
\text { YanShu(2016) }\end{array}$ \\
\hline $\begin{array}{l}\text { Information } \\
\text { Acceptance }\end{array}$ & $\begin{array}{l}\text { The passive information search behavior of fashion information in } \\
\text { fashion-based social media }\end{array}$ & Rha(2010), Shin(2016) \\
\hline $\begin{array}{l}\text { Information } \\
\text { Diffusion }\end{array}$ & $\begin{array}{l}\text { Use behavior that affects others by sharing information of fashion-based } \\
\text { social media }\end{array}$ & Rha(2010), Shin(2016) \\
\hline Purchase Intension & $\begin{array}{l}\text { Willing to purchase fashion goods using fashion information from social } \\
\text { media }\end{array}$ & Aaker(1991), Kim \& Shin(2014) \\
\hline
\end{tabular}




\section{4. 자료수집 및 분석방법}

본 연구는 패션 소셜미디어 품질과 패션정보 이용행동, 구 매의도 간의 인과관계를 알아보고자 하였다. 이에 따라 패션 기반 소셜미디어를 활용하여 패션 정보를 탐색, 활용한 경험이 있는 패션 소비자를 대상으로 설문조사를 실시하였다.

한국인터넷진흥원에서 발표한 인터넷이용실태조사에 의하면 연령대별 SNS 이용률이 20대는 $91.5 \%, 30$ 대는 $83.9 \%, 40$ 대 가 $69.5 \%$ 순이었다. 따라서 연구 대상을 이용률이 높은 20 40대로 한정하였다(Korea Internet \& Security Agency, 2017).

설문지 구성은 선행연구를 토대로 하여 검증된 문항과 본 연구에 맞게 수정, 보완한 항목들로 구성하여 본 조사에 앞서 사전조사를 실시하였다. 사전조사는 패션기반 소셜미디어 이용 경험자를 대상으로 238부를 2017월 6월 24일부터 2017년 6 월 27 일까지 조사하였으며, 불성실한 응답을 제외한 216부의 분석을 통해 설문지를 수정, 보완하였다.

본 조사의 설문은 2018년 3월 12일부터 2018년 3월 16일까지 5 일간 온라인 리서치 전문기업인 글로벌 리서치에 조사 의뢰하였 다. 총 4,177 부를 발송한 후 1,188 부를 회수하였으며, screening test를 거친 773 부 가운데 설문에 있어서 일관성이 없거나 불성실 한 응답을 제거한 후 최종 755 부를 결과분석에 사용하였다.

조사 대상자의 인구통계학적 특성은 다음과 같다. 성별은 남성 이 387 명 $(51.3 \%)$, 여성이 368 명 $(48.7 \%)$ 으로 나타났고, 연령은 20 대 가 222명(29.4\%), 30대가 294명(38.9\%), 40대가 239명(31.7\%)으로 조사되었다. 응답자의 결혼여부는 미혼이 397 명 $(52.6 \%)$, 기혼이 358 명(47.4\%)으로 나타났으며, 교육수준은 대학교 졸업이 431명 (57.1\%)으로 전체의 $50 \%$ 이상을 차지하였고, 전문대 졸업이 97 명 $(12.8 \%)$, 고졸 이하 85 명 $(11.3 \%)$, 대학교 재학이 68 명( $(9 \%)$, 대학원
재학 이상 62 명(8.2\%), 전문대 재학이 12 명(1.6\%)으로 나타났다.

본 연구에서는 가설을 실증적으로 분석, 검증하기 위해서 설 문조사를 통해 수집된 자료를 SPSS 23.0과 AMOS 23.0 통계 프로그램을 사용하여 분석하였다. 본 연구의 측정항목은 이론적 배경을 토대로 선행연구들에서 추출, 구성하였으며, 사전조사를 통해 내용 타당성과 내적 일관성 여부를 판단하였다. 본 조사를 통해 수집된 자료를 바탕으로 각 변수의 하위차원을 구성하였 고, Cronbach's Alpha 계수를 통해 내적 일관성을 검증하였다. 또한 확인적 요인분석을 통해 측정모형의 타당성을 검증하였다. 연구모형에 제시된 구성개념간 인과관계를 검증하기 위해 구조 방정식모델링(Structural Equation Modeling: SEM)을 실시하였다.

\section{4. 실증분석}

\section{1. 신뢰성 및 타당성 분석}

본 연구에서는 변수의 타당성 분석을 위해 탐색적 요인분석 을 실시하였으며, 탐색적 요인분석 방법으로 주성분분석 (principal component analysis)방식을 이용하였다. 요인행렬 회전 은 베리맥스(varimax)방식을 이용하였고, 고유값(eigenvalue)이 1 이상인 요인만을 추출하였다. 패션 기반 소셜미디어 품질 문 항들에 대한 탐색적 요인분석 실시 결과는 다음과 같다. 패션 소셜미디어 품질의 하위차원은 요인부하량이 낮은 항목을 제 외하고 0.5 이상으로 구성된 총 4 개의 요인이 도출되었으며, 구성 요인들의 총 설명력은 $60.09 \%$ 로 나타났다. 그 결과는 $<$ Table 2>와 같다. $\mathrm{KMO}$ 와 Bartlett의 검정결과, 표본 적합도의 Kaiser-Meyer-Olkin(KMO) 측도는 .947로 $\mathrm{KMO}>.5$ 을 만족하므 로 요인분석을 실시하는 것이 적절하다고 판단할 수 있다.

Table 2: Results of Exploratory Factor Analysis and Reliability Analysis

\begin{tabular}{|c|c|c|c|c|}
\hline (In) The social media I use (is) & $\begin{array}{l}\text { Information } \\
\text { Quality }\end{array}$ & $\begin{array}{l}\text { Social } \\
\text { Quality }\end{array}$ & $\begin{array}{l}\text { Service } \\
\text { Quality }\end{array}$ & $\begin{array}{l}\text { System } \\
\text { Quality }\end{array}$ \\
\hline 7. Visual fashion information has an aesthetic value. & .76 & & & \\
\hline 8. Visual fashion information is sensible. & .75 & & & \\
\hline 1. The latest fashion information is provided. & .69 & & & \\
\hline 3. Fashion information is interesting. & .67 & & & \\
\hline 4. Fashion information is useful. & .63 & & & \\
\hline 6. Fashion information contains various and abundant contents. & .55 & & & \\
\hline 9. Visual fashion information is artistic. & .54 & & & \\
\hline 5. Fashion information is easy to understand. & .50 & & & \\
\hline 17. It improves my image toward other users, friends, or colleagues. & & .77 & & \\
\hline 16. Networking gives me a sense of belonging. & & .75 & & \\
\hline 19. It helps build a new networking opportunity inthe field of interest. & & .74 & & \\
\hline 20. It provides an opportunity to communicate with many people. & & .69 & & \\
\hline 18. It enables me to help other users. & & .64 & & \\
\hline 15. If my family, co-workers, friends use it, I feel I would be better off using it as well. & & .59 & & \\
\hline 13. Fashion-related Information providers promptly respond to request and questions. & & & .73 & \\
\hline 11. I trust fashion-related information providers. & & & .71 & \\
\hline 12. Fashion-related information providers have required knowledge and ability. & & & .69 & \\
\hline $\begin{array}{l}\text { 14. Fashion-related information providers pay attention to the user's request and interest } \\
\text { and provide personalized services. }\end{array}$ & & & .65 & \\
\hline 10. Fashion-related information providers offer a wide range of services. & & & .57 & \\
\hline 21. It is easy to post (photos, comments, etc). & & & & .78 \\
\hline 23. It is easy to use. & & & & .77 \\
\hline 22. It is easy to access contents. & & & & .76 \\
\hline Eigen value & 4.03 & 3.69 & 3.02 & 2.48 \\
\hline Variance(\%) & 18.30 & 16.77 & 13.73 & 11.29 \\
\hline Cumulative variance(\%) & 18.30 & 35.07 & 48.80 & 60.09 \\
\hline Cronbach's $\alpha$ & 0.866 & 0.869 & 0.833 & 0.813 \\
\hline
\end{tabular}


요인분석 결과 요인 1은 패션 기반 소셜미디어의 패션정보 에 대해 최신의, 흥미롭고, 유용하며, 다양하고, 이해하고 쉽 고, 시각적인 미적매력과 감각, 예술적 정보이다라는 내용으로 써 적재치가 낮은 1문항이 제거되어 8문항으로 구성되었으며, 패션 소셜미디어 정보품질로 명명하였다. 고유치는 4.03, 전체 분산의 $18.30 \%$ 를 설명하는 것으로 나타났다.

요인 2는 패션 기반 소셜미디어가 소속감을 느끼게 해주고, 지인의 이용으로 나도 이용하는 것이 좋다고 느끼고, 다른 이 용자나 지인에게 나의 이미지를 좋게 해주고, 다른 이용자에게 도움을 줄 수 있게 해주며, 새로운 인맥 형성에의 도움 정도와 많은 사람들과 교류의 장을 마련해준다는 내용으로 6 문항 구 성되었으며, 패션 소셜미디어 사회성품질로 명명하였다. 고유 치는 3.69 , 전체분산의 $16.77 \%$ 를 설명하였다.

요인 3은 패션 기반 소셜미디어의 정보제공자의 다양한 서비스 제공, 정보제공자에 대한 신뢰, 정보제공자의 관련 분야에 대한 지식과 능력, 정보제공자의 신속하고 개인화된 서비스 제공 등의 내용으로 5 문항 구성되었으며 패션 소셜미디어 서비스품질이라고 명명하였다. 고유치는 3.02 , 전체분산의 $13.73 \%$ 를 설명하였다.

요인 4는 패션 기반 소셜미디어의 사용 용이성, 콘텐츠 접 근의 이용 편의성 등을 지각한다는 내용을 담고 있는 3 문항으 로 구성되었고, 적재치가 낮은 2문항은 제거되었다. 패션 소셜 미디어 시스템품질로 명명하였고, 고유치는 2.48 , 전체분산의 $11.29 \%$ 를 설명하는 것으로 나타났다.

본 연구에서 실시한 패션 소셜미디어 품질 구성개념의 신뢰 도 검정 결과, 패션 소셜미디어 정보품질은 .866 , 사회성품질은 .869 , 서비스품질은 .833 , 시스템품질은 .813으로 Cronbach's $\alpha$ 계수가 0.8 이상이므로 허용 가능한 신뢰도를 나타내고 있 다고 볼 수 있다.

패션 기반 소셜미디어를 통한 패션 정보 이용행동과 구매의
도 문항들에 대한 탐색적 요인분석을 실시한 결과는 <Table 3> 과 같다. 패션정보 이용행동과 구매의도 하위차원은 요인부하량 이 낮은 항목을 제외하고 0.5 이상으로 구성된 총 3 개의 요인이 도출되었으며, 구성 요인들의 총 설명력은 $67.03 \%$ 로 나타났다.

$\mathrm{KMO}$ 와 Bartlett의 검정결과, 표본 적합도의 Kaiser-MeyerOlkin $(\mathrm{KMO})$ 측도는 .95로 $\mathrm{KMO}>.5$ 를 만족하였다. 또한 Bartlett 의 값이 $p=.000$ 으로 $p<.05$ 이면 대각행렬이 아님을 의미하므로 요인분석을 하는 것이 적절하다고 할 수 있다.

요인 1은 패션 기반 소셜미디어에서 댓글을 단다. 지인 태 그, 게시물 공유 및 업로드, 패션 제품 구매 후 정보 공유, 패 션에 관련된 나의 경험을 올린다는 내용으로써 7 문항으로 구 성되어 패션 소셜미디어 정보확산으로 명명하였다. 고유치는 4.87 이었고, 전체분산의 설명력은 $30.46 \%$ 로 나타났다.

요인 2는 패션기반 소셜미디어의 패션정보를 활용하여 패션 제품을 구매할 의향, 추천할 의향, 패션관련 게시물, 댓글 등 을 보고 구매에 영향을 미칠 것이다, 패션관련 게시물을 보고 난 후, 구매 경향의 내용으로써 4문항으로 구성되었으며, 구매 의도로 명명하였다. 고유치는 2.96 , 전체분산의 $18.50 \%$ 를 설 명하는 것으로 나타났다.

요인 3은 패션 기반 소셜미디어에서 타인이 업로드한 패션관 련 정보를 읽는다, 사진 및 동영상을 본다, 특정 사람이나 게시 물을 검색한다, 패션관련 게시물, 댓글, 리뷰를 보면 영향을 받 는다는 내용으로 5 문항 구성되었으며, 패션 소셜미디어 정보 수 용으로 명명하였다. 고유치는 2.89 , 전체분산의 $18.07 \%$ 를 설명 하는 것으로 나타났다.

본 연구에서 실시한 패션정보 이용행동과 구매의도 구성개 념의 신뢰도 검정 결과, 정보수용은 .834, 정보확산은 .921, 구 매의도는 .837 로 Cronbach's $\alpha$ 계수가 0.8 이상이므로 허용 가능한 신뢰도를 나타내고 있다.

Table 3: Results of Exploratory Factor Analysis and Reliability Analysis

\begin{tabular}{|c|c|c|c|}
\hline In social media, I & $\begin{array}{l}\text { Information } \\
\text { acceptance }\end{array}$ & $\begin{array}{l}\text { Purchase } \\
\text { Intention }\end{array}$ & $\begin{array}{l}\text { Information } \\
\text { Diffusion }\end{array}$ \\
\hline 35. I upload fashion-related posts (texts, photos, etc). & 0.83 & & \\
\hline 33. I tag my friends in fashion-related posts uploaded by others. & 0.82 & & \\
\hline 37. I post my fashion-related experiences. & 0.80 & & \\
\hline 34. I share fashion-related posts uploaded by others. & 0.80 & & \\
\hline 36. I share information after the purchase of fashion-related products. & 0.77 & & \\
\hline 31. I leave comments on fashion-related posts uploaded by others. & 0.75 & & \\
\hline 32. I click 'Like' on fashion-related posts others uploaded. & 0.58 & & \\
\hline $\begin{array}{l}\text { 40. Reading fashion-related posts, comments, reviews on social media will have influence on } \\
\text { my future fashion product purchase. }\end{array}$ & & 0.75 & \\
\hline 38. I am willing to purchase fashion products based on fashion information on social media. & & 0.74 & \\
\hline 41. I tend to purchase products after seeing fashion-related posts on social media. & & 0.74 & \\
\hline $\begin{array}{l}\text { 39. I am willing to encourage others to buy fashion products based on the information I get } \\
\text { on social media. }\end{array}$ & & 0.66 & \\
\hline 26. I read fashion-related information uploaded by others. & & & 0.80 \\
\hline 27. I see fashion-related photos uploaded by others. & & & 0.74 \\
\hline 28. I watch fashion-related videos uploaded by others. & & & 0.69 \\
\hline $\begin{array}{l}\text { 29. I search fashion-related people or specific posts (i.e. hashtag search on Instagram, } \\
\text { friend search or post search on Facebook) }\end{array}$ & & & 0.59 \\
\hline 30. I am influenced by fashion-related posts, comments, and reviews, etc. & & & 0.50 \\
\hline Eigen value & 4.87 & 2.96 & 2.89 \\
\hline Variance(\%) & 30.46 & 18.50 & 18.07 \\
\hline Cumulative variance(\%) & 30.46 & 48.96 & 67.03 \\
\hline Cronbach's $\alpha$ & 0.921 & 0.837 & 0.834 \\
\hline \multicolumn{4}{|l|}{$\mathrm{KMO}=0.950$, Barlett's test $\chi 2=7243.970(\mathrm{df}=120, p<0.001)$} \\
\hline
\end{tabular}


탐색적 요인분석으로 도출된 각 구성개념의 항목에 대한 단 일 차원성 및 척도의 집중타당성을 검정하기 위하여 확인적 요 인분석(Confirmatory Factor Analysis: CFA)을 실시하였다.

패션 소셜미디어 품질(정보품질, 사회성품질, 서비스품질, 시스 템품질), 패션정보 이용행동(정보수용, 정보확산)과 구매의도 측정 항목의 타당성 검정을 위한 확인적 요인분석을 실시한 결과 모형 의 적합도는 다음과 같다. 카이제곱 $\left(\chi^{2}\right)$ 값은 1870.734 , 자유도(df) 는 $644, \mathrm{p}$ 값이 0.000 으로 $\chi^{2}$ 값에 대한 $\mathrm{p}$ 값은 기준을 충족시키지 않아, 부적합한 것으로 나타났다. 하지만 $\chi^{2}$ 통계량은 표본의 크 기가 커질수록 모형이 적합하지 않은 것으로 보고되는 경향이 있 기 때문에, 본 연구에서는 표본 수에 민감하지 않은 RMR, GFI, $\mathrm{NFI}$, 등의 적합도 지수에 의하여 측정모형의 적합도를 판단하였 다(Woo, 2012; Lee \& Im, 2017). $\chi^{2} / \mathrm{df}$ 값이 2.905로 3 이하이고, $\mathrm{RMR}$ 값이 0.040으로 0.05보다 낮고, GFI값이 0.877, AGFI값이 $0.858, \mathrm{NFI}$ 값이 0.889 로 0.8 보다 높고, 0.9 에 가까운 것으로 나타
나 수용 가능한 범위에 있어 측정모형은 적합하다고 판단하였다. 구성개념의 집중타당성은 요인부하량과 유의성, $\mathrm{CR}$ (개념신뢰 도), $\mathrm{AVE}$ (평균분산추출)을 통해 검증하였다. 본 연구모형에서는 잠재변수에서 관측변수로 가는 모든 경로의 표준화 회귀계수 (Standardized Estimates) 값 .5(.585 .827) 이상, CR 값은 모두 .7 이상(.87 .92)와 AVE는 기준치 .5 이상(.56 .71)으로 집중 타 당성이 검증되어 측정하고자 하는 변수의 개념을 허용 가능한 수준으로 정확하게 측정하였다고 판단하였고, 내적일관성을 확 보하였다. 그러므로 본 연구에 사용된 측정변수는 집중타당성이 있다고 판단하였다. 본 연구모형의 구성개념 별 측정변수들에 대한 집중타당성 검증결과는 <Table $4>$ 와 같다.

$<$ Table 5>는 본 연구에서 판별타당성 검증을 위해 AVE 값과 결정계수의 비교하여 분석한 결과이다. 상관계수는 구성개념들 의 평균치를 이용하여 산출하였다. 그 결과 $\mathrm{AVE}$ 값이 모든 잠 재변수 간 결정계수보다 크게 나타나 판별타당성을 확인하였다.

Table 4: Results of confirmatory factor analysis

\begin{tabular}{|c|c|c|c|c|c|c|c|c|c|}
\hline Variables & & Estimate & Standardised Estimate & S.E. & C.R. & p-value & error term & AVE. & CR. \\
\hline \multirow{8}{*}{$\begin{array}{c}\text { Information } \\
\text { Quality }\end{array}$} & 1 & 1.00 & 0.687 & & & & 0.28 & \multirow{8}{*}{0.59} & \multirow{8}{*}{0.92} \\
\hline & 3 & 1.13 & 0.722 & 0.06 & 18.04 & $0.000^{\star \star \star}$ & 0.29 & & \\
\hline & 4 & 1.03 & 0.693 & 0.06 & 17.37 & $0.000^{* \star *}$ & 0.29 & & \\
\hline & 5 & 0.89 & 0.585 & 0.06 & 14.82 & $0.000^{\star \star \star}$ & 0.38 & & \\
\hline & 6 & 1.07 & 0.661 & 0.06 & 16.62 & $0.000^{\star \star *}$ & 0.37 & & \\
\hline & 7 & 1.05 & 0.697 & 0.06 & 17.46 & $0.000^{\star \star *}$ & 0.29 & & \\
\hline & 8 & 1.09 & 0.732 & 0.06 & 18.25 & $0.000^{\star \star \star}$ & 0.25 & & \\
\hline & 9 & 0.94 & 0.593 & 0.06 & 15.01 & $0.000^{\star \star *}$ & 0.41 & & \\
\hline \multirow{6}{*}{ Social Quality } & 15 & 1.00 & 0.684 & & & $0.000^{\star \star \star}$ & 0.44 & \multirow{6}{*}{0.60} & \multirow{6}{*}{0.90} \\
\hline & 16 & 1.02 & 0.719 & 0.06 & 17.90 & $0.000^{* * *}$ & 0.38 & & \\
\hline & 17 & 1.11 & 0.771 & 0.06 & 19.07 & $0.000^{\star \star *}$ & 0.32 & & \\
\hline & 18 & 0.92 & 0.715 & 0.05 & 17.83 & $0.000^{\star \star *}$ & 0.31 & & \\
\hline & 19 & 1.09 & 0.752 & 0.06 & 18.64 & $0.000^{\star * *}$ & 0.35 & & \\
\hline & 20 & 0.97 & 0.721 & 0.05 & 17.96 & $0.000^{* * *}$ & 0.33 & & \\
\hline \multirow{5}{*}{$\begin{array}{l}\text { Service } \\
\text { Quality }\end{array}$} & 10 & 1.00 & 0.651 & & & $0.000^{\star \star \star}$ & 0.32 & \multirow{5}{*}{0.62} & \multirow{5}{*}{0.89} \\
\hline & 11 & 1.22 & 0.728 & 0.07 & 16.85 & $0.000^{\star * *}$ & 0.31 & & \\
\hline & 12 & 1.22 & 0.751 & 0.07 & 17.26 & $0.000^{* * *}$ & 0.27 & & \\
\hline & 13 & 1.12 & 0.671 & 0.07 & 15.78 & $0.000^{\star * *}$ & 0.36 & & \\
\hline & 14 & 1.16 & 0.736 & 0.07 & 17.00 & $0.000^{* * *}$ & 0.27 & & \\
\hline \multirow{3}{*}{$\begin{array}{l}\text { System } \\
\text { Quality }\end{array}$} & 21 & 1.00 & 0.724 & & & $0.000^{\star * *}$ & 0.29 & \multirow{3}{*}{0.71} & \multirow{3}{*}{0.88} \\
\hline & 22 & 1.10 & 0.816 & 0.06 & 19.77 & $0.000^{* \star *}$ & 0.19 & & \\
\hline & 23 & 1.05 & 0.770 & 0.06 & 18.97 & $0.000^{\star * *}$ & 0.24 & & \\
\hline \multirow{5}{*}{$\begin{array}{l}\text { Information } \\
\text { acceptance }\end{array}$} & 26 & 1.00 & 0.740 & & & $0.000^{\star \star *}$ & 0.31 & \multirow{5}{*}{0.56} & \multirow{5}{*}{0.87} \\
\hline & 27 & 0.90 & 0.679 & 0.05 & 18.12 & $0.000^{\star \star \star}$ & 0.35 & & \\
\hline & 28 & 1.08 & 0.694 & 0.06 & 18.54 & $0.000^{\star \star *}$ & 0.47 & & \\
\hline & 29 & 1.13 & 0.730 & 0.06 & 19.53 & $0.000^{\star \star \star}$ & 0.42 & & \\
\hline & 30 & 1.05 & 0.711 & 0.06 & 19.00 & $0.000^{* \star *}$ & 0.40 & & \\
\hline \multirow{7}{*}{$\begin{array}{l}\text { Information } \\
\text { Diffusion }\end{array}$} & 31 & 1.00 & 0.785 & & & $0.000^{\star \star \star}$ & 0.40 & \multirow{7}{*}{0.61} & \multirow{7}{*}{0.92} \\
\hline & 32 & 0.88 & 0.689 & 0.04 & 20.05 & $0.000^{\star * \star}$ & 0.56 & & \\
\hline & 33 & 1.07 & 0.814 & 0.04 & 24.67 & $0.000^{\star \star \star}$ & 0.37 & & \\
\hline & 34 & 1.05 & 0.799 & 0.04 & 24.07 & $0.000^{\star * \star}$ & 0.40 & & \\
\hline & 35 & 1.07 & 0.814 & 0.04 & 24.66 & $0.000^{\star \star *}$ & 0.38 & & \\
\hline & 36 & 0.99 & 0.805 & 0.04 & 24.30 & $0.000^{\star * *}$ & 0.34 & & \\
\hline & 37 & 1.07 & 0.827 & 0.04 & 25.17 & $0.000^{\star \star \star}$ & 0.34 & & \\
\hline \multirow{4}{*}{$\begin{array}{l}\text { Purchase } \\
\text { Intention }\end{array}$} & 38 & 1.00 & 0.742 & & & $0.000^{\star \star *}$ & 0.28 & \multirow{4}{*}{0.64} & \multirow{4}{*}{0.88} \\
\hline & 39 & 1.11 & 0.760 & 0.06 & 20.24 & $0.000^{* * *}$ & 0.31 & & \\
\hline & 40 & 1.09 & 0.742 & 0.06 & 19.76 & $0.000^{\star \star *}$ & 0.33 & & \\
\hline & 41 & 1.13 & 0.755 & 0.06 & 20.11 & $0.000^{\star * *}$ & 0.33 & & \\
\hline
\end{tabular}


Table 5: Results of Discriminant Validity

\begin{tabular}{|c|c|c|c|c|c|c|c|}
\hline & \multicolumn{4}{|c|}{ Fashion Social Media Quality } & \multicolumn{2}{|c|}{ Information Usage Behavior } & \multirow{2}{*}{$\begin{array}{l}\text { Purchase } \\
\text { Intention }\end{array}$} \\
\hline & Information Quality & Social Quality & Service Quality & System Quality & Information acceptance & Information Diffusion & \\
\hline 1 & .59 & .285 & .336 & .315 & .410 & .106 & .367 \\
\hline 2 & $.534^{* *}$ & .60 & .456 & .212 & .359 & .419 & .416 \\
\hline 3 & $.580^{\star \star}$ & $.675^{\star \star}$ & .62 & .205 & .291 & .305 & .345 \\
\hline 4 & $.561^{\star \star}$ & $.460^{\star \star}$ & $.453^{\star *}$ & .71 & .333 & .049 & .213 \\
\hline 5 & $.641^{* \star}$ & $.599^{\star \star}$ & $.539^{* \star}$ & $.577^{\star \star}$ & .56 & .275 & .503 \\
\hline 6 & $.325^{\star \star}$ & $.647^{* \star}$ & $.552^{* \star}$ & $.222^{* *}$ & $.524^{\star \star}$ & .61 & .347 \\
\hline 7 & $.606^{\star \star}$ & $.645^{\star *}$ & $.587^{\star \star}$ & $.462^{\star *}$ & $.709^{\star \star}$ & $.589^{\star \star}$ & .64 \\
\hline \multicolumn{8}{|c|}{$\begin{array}{l}\text { ※*상관계수는 } 0.01 \text { 수준(양쪽)에서 유의함 } \\
\text { ※ 상관계수 제곱값 }=\mathrm{r} 2 \\
\text { ※ } \\
\quad \text { AVE 값 }\end{array}$} \\
\hline
\end{tabular}

\section{2. 가설검정 결과}

가설 검증을 위해 수립된 구조 모형의 모형적합도를 확인한 결과, $\quad \chi^{2} / \mathrm{df}=1.896, \quad \mathrm{RMR}=.029, \quad \mathrm{GFI}=.925, \quad \mathrm{AGFI}=.908$, $\mathrm{NFI}=.932$ 로 나타나 대부분의 적합도 지수는 기준치를 충족하 여 모형은 적합한 것으로 나타나, 구조방정식 모형(SEM)을 통 해 가설검정을 수행하였다. 본 연구에서 구조방정식 모형을 분 석한 결과는 Table 6, Figure 2와 같다. 패션기반 소셜미디어 품질과 정보수용과의 관계에서 설정한 가설 1_1, 가설 1_2, 가 설 1_4가 채택되었고, 가설 1_3은 기각되었다. 가설 1_1인 '정 보품질은 정보수용에 정(+)의 영향을 미칠 것이다.'에 대한 분 석 결과 두 잠재변수 간의 표준화 계수는 .486 이며 유의수준 $5 \%$ 이내에서 C.R. $=7.72(\mathrm{p}<.001)$ 로 나타나 통계적으로 유의한 것으로 판단되었으며, 가설 1_1은 채택되었다. 가설 1_2인 '사 회성품질은 정보수용에 정(+)의 영향을 미칠 것이다.'에 대한 분석 결과 두 잠재변수 간의 표준화 계수는 .324이고, 유의수 준 $5 \%$ 이내에서 C.R. $=5.53$ (p<.001)으로 나타나 통계적으로 유 의하여, 가설 1_2는 채택되었다. 가설 1_3인 '서비스품질은 정 보수용에 정(+)의 영향을 미칠 것이다.'에 대한 분석 결과, 두 잠재변수 간 표준화 계수는 .013이고, 유의수준 $5 \%$ 이내에서 C.R. $=0.21(\mathrm{p}=.831)$ 로 나타나 통계적으로 유의하지 않아, 가설 1_3은 기각되었다. 가설 1_4인 '시스템품질은 정보수용에 정 $(+)$ 의 영향을 미칠 것이다.'에 대한 분석 결과 두 잠재변수 간 의 표준화 계수는 .171 이며 유의수준 $5 \%$ 이내에서 C.R.=3.64 $(p<.001)$ 로 나타나 통계적으로 유의한 것으로 판단되었으며, 가설1_4는 채택되었다. 패션 소셜미디어 품질이 정보수용에 미치는 영향력은 정보품질, 사회성품질, 시스템품질 순으로 나 타났다. 이러한 결과는 정보품질 중 일부 요인이 수용의도에 유의한 영향을 미친다고 분석한 Lee(2017)의 연구를 부분적으 로 지지하였다. 또한, 정보품질과 시스템품질이 정보시스템 사 용에 영향을 미친다고 주장한 DeLone and McLean(2003)의 연구와 일치하였다.

서비스품질은 정보수용에 영향을 미치지 않는다는 결과는 DeLone and McLean(2003)의 연구와 반대되는 결과로 DeLone and McLean(2003)이 사용한 사용은 정보수용보다 포 괄적인 개념을 담고 있고, 또한 E-commerce의 품질에 대한 결과이기 때문인 것으로 사료되었다. 본 연구의 결과는 소셜미 디어의 특성이 반영된 것이라고 해석할 수 있다. 따라서 패션
기반 소셜미디어 사용자는 정보제공자에 대한 신뢰나 전문성 이확인되지 않아도 패션정보가 흥미롭거나 쉽게 얻을 수 있다 면 그 정보를 수용하는 것으로 사료되고, 이러한 소셜미디어에 서는 패션에 관심이 있는 일반인 사용자가 제공하는 패션정보 도 수용될 수 있는 가능성을 확인할 수 있다. 패션기반 소셜미 디어 품질과 정보확산과의 관계에서 설정한 가설 2_2, 가설 2_3, 가설 2_4가 채택되었고, 가설2_1은 기각되었다.

가설 2_1인 '정보품질은 정보확산에 정 $(+)$ 의 영향을 미칠 것 이다.'에 대한 분석 결과 두 잠재변수 간 표준화 계수는 -.034 이며, C.R. $=-.054(p=590)$ 로 나타나 통계적으로 유의하지 않아 가설 2_1은 기각되었다. 가설 2_2인 '사회성품질은 정보확산에 정(+)의 영향을 미칠 것이다.'에 대한 분석 결과 두 잠재변수 간의 표준화 계수는 .693 이며 유의수준 $5 \%$ 이내에서 C.R. $=10.20(p<.001)$ 으로 나타나 통계적으로 유의한 것으로 판 단되었으며, 가설 2_2는 채택되었다. 가설 2_3인 '서비스품질 은 정보확산에 정(+)의 영향을 미칠 것이다.'에 대한 분석 결과 두 잠재변수 간의 표준화 계수는 .238이고, 유의수준 $5 \%$ 이내 에서 C.R. $=3.56(\mathrm{p}<.001)$ 으로 나타나 통계적으로 유의하여, 가 설 233은 채택되었다. 가설 24인 '시스템품질은 정보확산에 정(+)의 영향을 미칠 것이다.'에 대한 분석 결과 두 잠재변수 간의 표준화 계수는 .213 이며 유의수준 $5 \%$ 이내에서 C.R. $=4.23$ (p<.001)으로 나타나 통계적으로 유의한 것으로 판단 되었으며, 가설 2_4는 채택되었다. 패션 소셜미디어 품질이 정 보확산에 미치는 영향력은 사회성품질, 서비스품질, 시스템품 질 순으로 나타났다. 시스템품질, 서비스품질이 정보시스템 사 용에 영향을 미친다고 주장한 DeLone and McLean(2003)의 연구와 일치하는 결과이다. 정보를 확산하는 행동에는 인터랙 션과 관련된 품질인 사회성 품질과 서비스 품질과 기능적인 편리함과 우수성인 시스템 품질에 대한 인식과 지각이 중요하 게 작용함을 알 수 있었다. 정보품질 지각은 정보확산에 영향 을 미치지 않는다는 결과는 정보품질 중 적시성, 상호성, 이해 성이 확산의도에 유의한 영향을 미치지 않았다고 분석한 Lee(2017)의 연구와 부분적으로 일치하였다. 이는 정보 그 자 체에 대한 품질은 확산행동과는 연관성이 작용하지 않음을 알 수 있고, 이러한 이유에 대해 패션 제품에 대한 정보이기에 이 러한 결과가 가능하다고 사료되고, 매력적인 패션정보를 여러 사람에게 확산하지 않을 수 있다고 여겨진다. 
Table 6: Test of Hypothesis

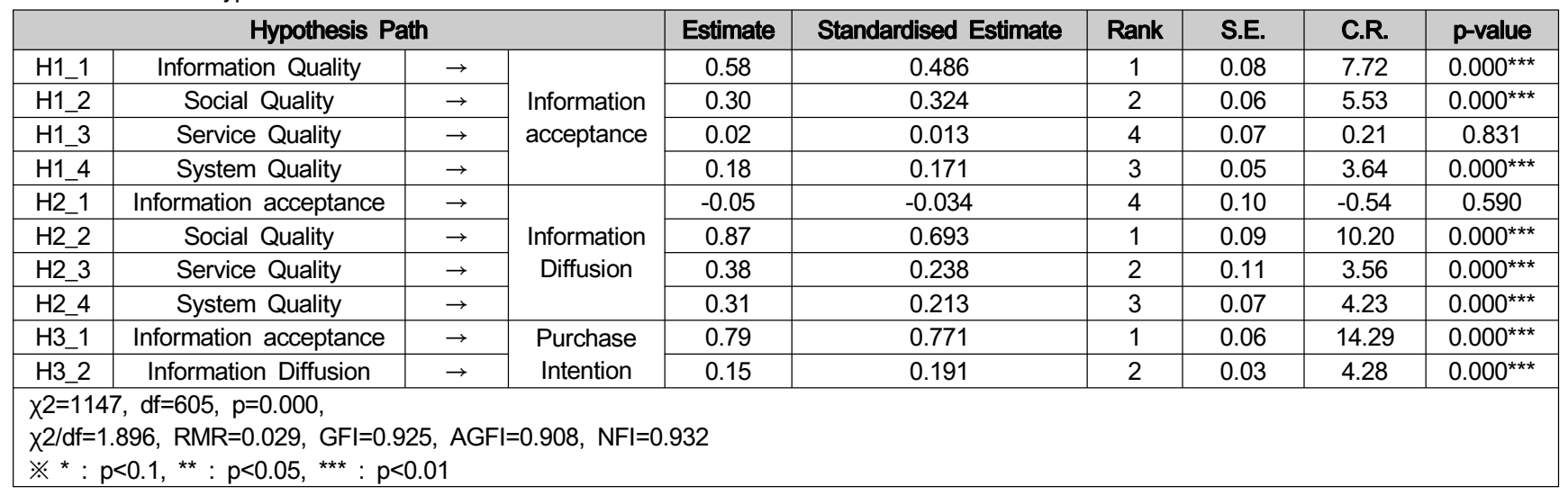

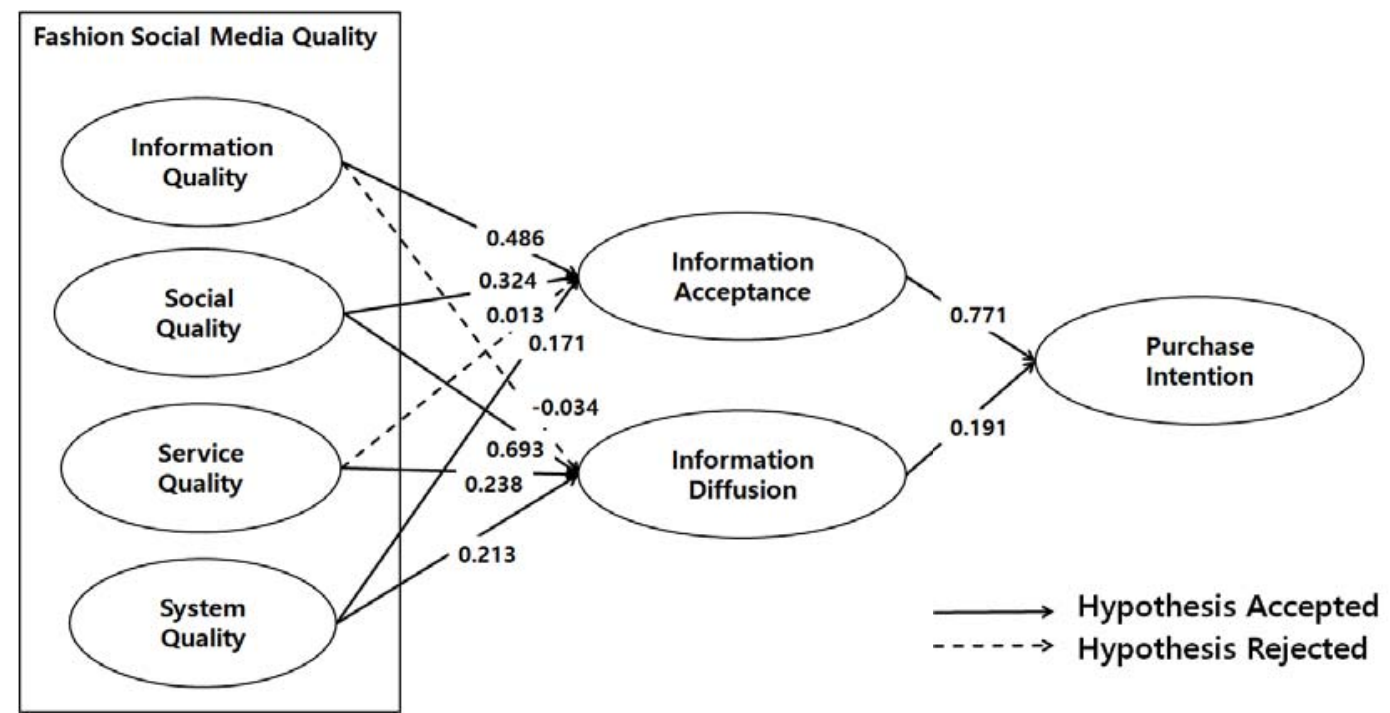

Figure 2: Results of Research Model

패션기반 소셜미디어를 통한 정보 이용 행동과 구매의도의 관계에 대하여 설정한 가설 3은 모두 채택되었다. 가설 3_1인 '정보수용은 구매의도에 정(+)의 영향을 미칠 것이다.'에 대한 분석 결과 두 잠재변수 간의 표준화 계수는 .771 이며 유의수 준 5\% 이내에서 C.R. $=14.29$ (p<.001)로 나타나 통계적으로 유 의한 것으로 판단되었으며, 가설 3_1는 채택되었다. 가설 3_2 인 '정보확산은 구매의도에 정(+)의 영향을 미칠 것이다.'에 대 한 분석 결과 두 잠재변수 간의 표준화 계수는 .191이고, 유의 수준 $5 \%$ 이내에서 C.R. $=4.28$ (p<.001)로 나타나 통계적으로 유 의하여, 가설 3_2는 채택되었다. 정보 이용행동이 구매의도에 미치는 영향에 대한 가설 3 은 모두 지지되었다. 이와 같은 결 과는 정보 제공적 공유 성향이 SNS와 결합한 인터넷 상거래 사용 경향에 영향을 미친다고 분석한 Han and Lee(2014)의 연구를 지지하였다. 또한 정보를 이용하려는 의도가 구매의도 나 추천의도에 영향을 미친다고 주장한 Lee and Nam(2015) 의 연구와도 일맥상통한 결과로 나타났다.

영향력 크기를 비교하면 정보수용이 정보확산보다 더 큰 것 으로 나타났다. 이는 러킹(lurking)을 하는 소극적인 정보수용
자가 소셜미디어에서 중요한 사용자임을 확인할 수 있는 결과 로 여겨진다. 또한, 정보확산행동은 보다 적극적인 정보해석이 수반되고, 이로 인한 감정과 인식이 긍정적, 부정적 두 방향으 로 모두 흐를 수 있기 때문인 것으로 사료된다.

\section{5. 결론 및 시사점}

소셜미디어를 활용하여 패션정보를 수용, 확산하는 패션소 비자가 늘어남에 따라 사용자가 중요하게 지각하는 소셜미디 어 품질과 소셜미디어에서의 패션정보의 수용과 확산, 적극적 인 활용을 할 것으로 여겨지는 개인 특성에 주목할 필요가 있 다. 본 연구에서는 패션 기반 소셜미디어를 이용하여 패션 정 보를 탐색, 활용한 경험이 있는 패션소비자를 대상으로 최종 755 부의 표본을 토대로 하여 패션기반 소셜미디어 품질의 하 위차원을 구성하였고, 패션 소셜미디어 품질이 패션정보 이용 행동과 구매의도에 미치는 영향을 규명하였다.

본 연구의 결과는 다음과 같다. 
첫째, 패션 기반의 소셜미디어 품질 하위차원을 구성하기 위하여 기존 소셜미디어 품질의 연구를 토대로 수정 보완하여 패션 기반의 특성을 반영한 소셜미디어 품질 하위차원은 패션 소셜미디어 정보품질, 사회성품질, 서비스품질, 시스템품질로 구성되었다. 패션 소셜미디어 품질, 정보 이용행동, 구매의도, 마켓메이븐 성향, 패션관여도의 측정도구와 패션 소셜미디어 품질, 정보이용행동, 구매의도의 측정모형의 신뢰도와 타당성 은 검증되었다.

둘째, 패션 소셜미디어 품질과 패션정보 이용행동, 구매의도 간 인과관계의 구조모형의 적합도를 검증하였다. 인과관계 분 석결과, 정보품질, 사회성품질, 시스템품질 순으로 정보수용에 영향을 미쳤고, 서비스품질은 정보수용에 영향을 미치지 않는 것으로 나타났다. 사회성품질, 서비스품질, 시스템품질 순으로 정보확산에 영향을 미쳤고, 정보품질은 정보확산에 영향을 미 치지 않는 것으로 나타났다. 정보수용, 정보확산 순으로 구매 의도에 영향을 미쳤다.

본 연구의 결과를 토대로 하여 도출된 학문적 시사점은 다 음과 같다. 첫째, 패션 소셜미디어 품질 요인의 구성 요소와 측정 변수를 규명함으로써 소셜미디어가 마케팅 도구로서 활 발하게 활용되는 상황에서 패션 기반 소셜미디어의 품질 요인 을 구성하였고, 일반적인 소셜미디어 품질 연구에서 많이 다루 어지지 않았던 사회성품질에 대한 중요성을 밝혀, 향후 패션 관련 소셜미디어 연구의 기초자료 제공에 기여한 점이다. 둘 째, 패션 소셜미디어 품질 지각을 통한 정보의 탐색과 활용, 구매의도까지 연결되는 패션 기반 소셜미디어의 활용에 관한 소비자관점의 통합적인 연구모형을 규명하여 향후 연구의 구 조적 체계화에 이바지한 점이다. 또한, 정보시스템 성공모형과 패션 소셜미디어의 활용, 패션 소비자의 구매행동과의 학술적 연계성을 밝히고, 보다 발전적인 품질 요인 및 행동 요인을 구 성하여 연구모형을 구축하고, 실증분석 하였다는 점이다. 정보 시스템 성공모형에서 정보품질, 시스템품질, 서비스품질로만 구성하였던 품질요인을 본 연구에서는 소셜미디어라는 정보시 스템에서 중요한 특성을 반영하는 사회성품질을 추가하였고, 행동요인도 정보수용, 확산으로 세분화하여 연구를 진행하였다.

패션 소셜미디어를 활용한 마케팅에 적용 가능한 실무적 시 사점은 다음과 같다. 첫째, 패션 소셜미디어를 통한 소극적인 정보 이용 행동인 정보를 보고, 읽는 등의 러킹(Lurking) 행동 을 유발하기 위해서는 패션 정보의 흥미, 유용성, 시각적인 패 션정보의 미적 매력 등의 정보 그 자체에 대한 품질을 높이는 것이 가장 중요하다고 해석할 수 있을 것이다. 그 다음으로는 소비자가 소속감을 느끼게 하거나, 새로운 인맥형성을 도와주 는 등 교류를 통한 관계 형성이 가능하다고 여기면 정보 수용 에 더욱 적극적일 것으로 예상된다. 마지막으로 콘텐츠 접근 및 게시물 등록이 용이하고, 전반적으로 이용하기 편리한 시스 템을 제공한다면 패션 소셜미디어를 통해 정보 수용이 활성화 될 것이다. 즉, 최신의 정보를 제공하고, 관계 형성이 가능하 며, 사용하기에 어려움이 없으면 그 정보를 수용하여 그 정보 를 바탕으로 구매하거나 다른 사람에게 추천하려는 의향이 생 기는 것으로 사료된다.

둘째, 패션 소셜미디어 이용자가 댓글 형태로 자신의 의견 을 작성하거나 자신의 패션관련 경험을 공유하는 행동을 일으 키려면 소통의 장을 더욱 활성화시키고, 새로운 인맥을 형성해 나가고, 그것으로 인해 자신이 누군가에게 도움이 될 수 있다 는 지각이 중요하게 작용할 것이다. 또한 패션 소셜미디어의 정보 제공자에 대한 신뢰와 정보 제공자의 능력에 대한 확신
은 적극적인 정보확산활동을 촉진시킬 것으로 여겨진다. 마지 막으로 게시물 등록이 용이하고, 전반적으로 이용하기 쉽고, 편리한 시스템을 제공한다면 패션 소셜미디어를 통해 정보 확 산이 활성화될 것이다. 또 한 가지 주목할 점은 정보의 다양성 등의 정보 그 자체에 대해 우수하게 지각하는 것은 정보확산 행동에 영향을 미치지 않았다는 점이다. 즉, 패션 소셜미디어 이용자 간의 정보확산을 활성화하려면 사람과의 관계를 바탕 에 둔 인터랙션과 관련된 요소, 즉 신뢰와 활성화 가능성 제시 가 중요함을 의미하고, 매력적이고 우수한 정보를 다른 사람과 공유하고 싶지 않은 심리와 자신만의 컨텐츠를 확산하고자 하 는 특성에 관심을 가져야 할 것으로 사료된다. 또한 다른 이용 자와의 소통, 정보제공자에 대한 긍정적인 인식과 시스템의 사 용용이성은 정보확산행동을 매개로 구매까지 연결될 가능성을 높일 수 있는 품질로 중요하게 다루어져야 할 것이다.

셋째, 패션 소셜미디어에서 정보를 수용하거나 확산하는 행 동은 보거나 댓글을 단 정보에 대한 패션 제품을 구매하려는 의향으로 이어질 것이다. 따라서 패션 소셜미디어에서 정보 이 용행동을 많이 하게 해야 할 것이고, 이에 영향을 미칠 수 있 는 품질 강화전략을 세워야 할 것이다. 정보확산활동을 하게 되면 보다 적극적인 정보 해석을 하게 되고, 그에 따르는 감정 과 인식이 긍정적으로 미칠지 부정적으로 미칠지 알 수 없기 때문에 의견을 끌어다 나르는 적극적인 이용자들의 대한 대비 전략도 필요하다. 소극적인 정보를 받아들이는 정보수용자들이 구매하려는 경향이 더 높은 것으로 보아, 이러한 소극적인 정 보 이용자들에게 관심을 가져야 할 것으로 여겨진다.

소셜미디어를 통한 패션 마케팅은 기존의 매체에 비해 적은 비용으로 높은 가능성을 보여준다는 면에서 누구에게나 열려 있다고 할 수 있다. 새로운 소셜미디어 계정을 기획하여 브랜 드를 성장시키려고 하는 신진 디자이너 브랜드, 개인 미디어를 통해 패션 관련 제품 판매를 원하는 개인, 기존의 브랜드 소셜 미디어에서 새로운 정보를 기획하여 게시하고자 하는 실무자들 은 주요 타깃 이용자의 특성을 파악하고, 그 특성에 따른 전략 수립과 이용자가 정보를 수용하고 다른 사람에게 제공하게 하는 데 있어서 중요하게 지각하는 품질 요인을 파악, 이용자의 행위 와 구매의도를 이끌어 낼 수 있는 전략을 수립해야 할 것이다.

본 연구의 한계점과 이에 따른 향후 연구방향은 다음과 같 다. 첫째, 패션 소셜미디어를 통해 패션 정보를 접한 경험이 있는 이용자를 대상으로 조사를 실시하였지만, 이용 정도에 따 라 많은 시간을 투자하여 이용 하는 헤비 유저와 가끔 이용하 는 라이트 유저가 있었다. 따라서 향후, 패션 소셜미디어를 적 극적으로 이용하는 헤비유저만을 대상으로 연구가 이루어진다 면 더욱 영향력 있는 결과 도출이 가능할 것이다.

둘째, 패션정보 이용행동과 구매의도에 영향을 미치는 외생 변수를 패션 소셜미디어 품질변수 하나에 국한하여 연구하였지 만, 향후 연구에는 패션 소셜미디어 정보이용행동과 구매의도에 미치는 이용자의 개인 특성 등의 외생변수를 추가하거나 새롭 게 구성하여 연구가 진행된다면 보다 폭넓은 연구가 될 것이다.

\section{References}

Aaker, D. A., \& Equity, M. B. (1991). Capitalizing on the value of a brand name. New York, NY: The Free Press. Ahn, D. H., \& Han, G. J. (2011). The Effects of SNS(Social 
Networking Service)Quality on Brand Reputation, Quality Satisfaction and Purchase Intention in the Foodservice Industry. Journal of Foodservice Management, 14(4), 169-188.

Ahn, E. M. (2013). Consumer Psychology. Seoul, South Korea: Parkhaksa.

Ahn, K. H., \& Lee, Y. J. (2002). The Study of the Influence of Consumer's Shopping Orientation on the Relationship between Store image variables and On-line Consumer's Purchase Intention. Journal of Consumer Studies, 13(4), 101-122.

Bae, J. K. (2013). A Study of Influencing Factors for Repurchase Intention in Social Commerce Services. The e-Business Studies, 14(2), 199-224.

Boulding, W., Kalra, A., Staelin, R., \& Zeithaml V. A. (1993). A dynamic process model of service quality: From expectations to behavioral intentions. Journal of Marketing Research, 30(1), 7-27.

Burnett, G. (2000). Information exchange in virtual communities: A typology. Information research, 5(4).

Chae, B. S. (2018. 01. 04). What are the top six marketing trends of Instagram? Blotter. Retrieved May 17, 2018 from http://www.bloter.net/archives/299447

Chatterjee, P. (2001). Online reviews: Do consumers use them? Advances in Consumer Research, 28, 129-134.

Cho, C. H., \& Cheon, H. J. (2005). Cross-cultural comparisons of interactivity on corporate web sites: The United States, the United Kingdom, Japan, and South Korea. Journal of Advertising, 34(2), 99-115.

Cho, C. H., \& Leckenby, J. D. (1999). Interactivity as a measure of advertising effectiveness: Antecedents and consequences of interactivity in web advertising. Proceedings of the Conference of American Academy of Advertising, 162-179.

Cho, D. S., \& Lee, H. Y. (2015). Social Presence, Flow, and E-loyalty: The Moderating Role of Perceived Value in Restaurant Mobile Environments. Journal of Hospitality and Tourism Studies, 372), 187-211.

Cho, P. S., \& Kim, Y. T. (2014). Effects of SNS Quality on Customer Attitude and Brand Image in the Hotel Industry. Journal of Tourism and Leisure Research, 26(7), 217-237.

Choi, E. H. (2016). Start with women's social marketing. Seoul, South Korea: Sungandong.

Choi, J. Y. (2017). The Fourth Industrial Revolution And social media. Seoul, South Korea: Media book.

Choi, W. (2017). A Study on the Influence of Brand Position on Brand Loyalty and Purchase Intention. (Master dissertation, Khung Hee University). Retrieved December 10, 2017 from http://khu.dcollection.net/public_resource/ pdf /200000068357

DeLone, W. H., \& McLean, E. R. (1992). Information systems success: The quest for the dependent variable. Information Systems Research, 3(1), 60-95.

DeLone, W. H., \& McLean, E. R. (2003). The DeLone and McLean model of information systems success: A ten-year update. Journal of Management Information Systems, 194), 9-30.

Engel, J. F., Blackwell, R. D., \& Paul W. M. (1994). Consumer behavior (8th ed). Fort Worth, TX: The Dryden Press.

Fishbein, M., \& Ajzen, I. (1975). Belief, attitude, intention, and behavior: An introduction to theory and research reading. Boston, MA: Addison-Wesley.

Gao, L., Bai, X., \& Park, A. (2014). Understanding sustained participation in virtual travel communities from the perspectives of is success model and flow theory. Journal of Hospitality \& Tourism Research, 41(4), 475-509.

Gorla, N., Somers, T., \& Wong, B. (2010). Organizational impact of system quality, information quality, and service quality. Journal of Strategic Information Systems, 19(3), 207-228.

Han, H. J., \& Lee, K. M. (2014). Consumer Information Sharing in Social Media. Journal of Consumer Studies, 25(2), 21-44.

Han, H. J., \& Lee, K. M. (2014). Consumer Information Sharing in Social Media. Journal of Consumer Studies, 25(2), 21-44.

Hausman, A., \& Siekpe, J. (2009). The effect of web interface features on consumer online purchase intentions. Journal of Business Research, 62(1), 5-13.

Hoffman, D., \& Novak, T. (1996). Marketing in hypermedia computer-mediated environments: Conceptual foundations. Journal of Marketing, 60(3), 50-68.

Hur, K. S. (2016). Influence of Network characteristics and Information quality of Social media on the travel information sharing of social media users - Focucing on Source Credibility -. ournal of Tourism and Leisure Research, 18(3), 22-39.

Hyun, Y. H., Kim, Y. I., Nam, J. H., \& Kim, Y. S. (2014). A Study on the Acceptance Attitude of Social Commerce by Food Product Consumers: Applying Extended TAM. Journal of Tourism Sciences, 38(10), 57-79.

Jang, H. J. (2018. 04. 27). Those who are tasted at the table. The Kyunghyang Biz. Retrieved May 17, 2018 from http://biz.khan.co.kr/khan_art_view.html?artid=201804271654 005\&code $=900370$

Kalwani, M. U., \& Silk, A. J. (1982). On the reliability and predictive validity of purchase intention measures. Marketing Science, 1(3), 243-286.

Kettinger, W. J., \& Lee, C. C. (1997). Pragmatic perspectives on the measurement of information systems service quality. MIS Quarterly, 21(2), 223-240.

Kim, B. S., Shin, M. H., Im, D. K., \& Lee, I. H. (2013). Motivation and Types of Social Media Users in Their Social Network Activities. Social Science Research, 29(2), 105-134.

Kim, D. J., \& Hwang, D. H. (2012). The Effect of SNS(Social Networking Service) Quality on Satisfaction and Repurchase Intention in the Hotel Industry. International Journal of Tourism Management and 
Sciences, 24(5), 261-281.

Kim, J. Y. (2018. 01. 15). 2018 Fashion Technology Trends. M Economy News. Retrieved May 17, 2018 from http://www.m-economynews.com/news/article.html?no=21273

Kim, M. I., \& Lee, S. B. (2011). The Effect of Public Lifestyle on Motivation and Behavior Using Social Media. The Korean Journal of Advertising and Public Relations, 13(2), 306-341.

Kim, M. J., \& Shin, S. Y. (2014). Effects of mobile fashion shopping characteristics on perceived usefulness, perceived ease of use, purchase attitude, and purchase intention of mobile fashion shopping mall - Focusing on smartphone users -. The Research Journal of the Costume Culture, 22(2), 240-257.

Kim, S. K., Sung, H. N., \& Jeong, D. Y. (2007). What Quality Factors Affect to the e-Learning Performance. The Journal of Information Systems, 16(1), 201-230.

Kim, S. Y., \& Joo, Y. H. (2001). Perceived Interactivity and Web site Loyalty / On the Role of Flow as a Mediating Variable. Journal of Consumer Studies, 12(4), 185-208.

Ko, H. S., Kim C. S., Jung, M. Y., Oh. Y. J., \& Lee, S. H. (2011). The Effect of Social Network Service's Quality Factors on User Satisfaction and the Intention to Continued Use. Journal of Korean Society for Quality Management, 39(4), 543-555.

Kong, J. H., \& Sung, H. N. (2014). Study on Knowledge Sharing Motivation and Information Diffusion of the Web-Maven in the Foreign Direct Purchases Social Media Channels. The Journal of Internet Electronic Commerce Research, 16(3), 223-241.

Korea Internet \& Security Agency (2017. 03. 18). 2016 Internet Usage Survey. Korea Internet \& Security Agency. $\begin{array}{llll}\text { Retrieved April 29, } 2018 \text { from } & \text { 29 }\end{array}$ https://isis.kisa.or.kr/board/index.jsp?pageld=060100\&bbsld= 7\&itemld=817\&pagelndex $=1$

Kozinets, R. V., de Valck, K., Wojnicki, A. C., \& Wilner, S. S. (2010). Networked narratives: Understanding word-ofmouth marketing in online communities. Journal of Marketing, 74(2), 71-89.

Lee, A. G., \& Rhee, Y. J. (2018). The differences of online word-of-mouth acceptanceand re-delivery intention: Focusing on the interaction effects offashion involvement and market maven. The Research Journal of the Costume Culture, 26(2), 172-187.

Lee, E. Y. (2004). Two factor model of online word of mouth andoption and diffusion : the effects of information characteristics and community factors. (Doctorial dissertation, Seoul National University). Retrieved $\begin{array}{llll}\text { December } & 10, & 2017 & \text { from }\end{array}$ http://dcollection.snu.ac.kr/ezpdfdrm/dCollection.jsp?sltemld= 000000056309

Lee, H. S., \& Im, J. H. (2017). Structural Equation Model Analysis and AMOS 24. Seoul, South Korea: JypHyunJae Publishing Co.

Lee, H. S., \& Nam, G. Y. (2015). Social Networking
Services(SNS): Motivation, SNS Participation, and Behavioral Intention to Visit Restaurants. Journal of Tourism Sciences, 398), 151-168.

Lee, J. H., \& Lee, S. H., (2011). The Effects of Advertising with Social Media Participation Attitude as Fashion Brand Communities and UCC. Journal of the Korean Society of Clothing and Textiles, 35(8), 877-889.

Lee, J. S., \& Park, M. J. (2005). The Relationship Among Servicescape, Emotional Response and Behavior Intention in Hotel Restaurant. Journal of Korea Service Management Society, 6(2), 105-128.

Lee, M. K. (2017). Effect of the Mobile Tourism Information Quality of Tourists on Experience Value, Acceptance Intention and Diffusion Intention. Journal of Hotel \& Resort, 16(3), 223-241.

Lee, S. B. (2014). The Effects of National Police Agency's social media quality on the intention of continuous use. The Korean Association of Police Science Review, 45. 71-97.

Lee, S. H., \& Kim, M. S. (2012). The Effects of SNS Website Quality on User Satisfaction, Purchase Intentions and Brand Loyalty in a Hotel Industry. Journal of Tourism and Leisure Research, 24(5), 261-281.

Madden, T. J., Ellen, P. S., \& Ajzen, I. (1992). A comparison of the theory of planned behavior and the theory of reasoned action. Personality and Social Psychology Bulletin, 18(1), 3-9.

Mun, B. H. (2016). Social media changes consumers' future. Fashion Seoul. Retrieved December 10, 2017 from http://www.fashionseoul.com/120130

Parasuraman, A., Zeithaml, V. A., \& Berry, L. L. (1985). A conceptual model of service quality and its implications for future research. Journal of Marketing, 49, 41-50.

Park, H. J. (2007). A study on the improvement of information services based upon the analysis of information behaviors. (Doctorial dissertation, Chung-Ang University). Retrieved December 28, 2017 from https://library.cau.ac.kr/\#/search/detail/569007

Park, J. Y. (2014). Effects of SNS Interaction Word of Mouth and Purchase Intention: Focusing on Motivatins for Use of Facebook. (Doctorial dissertation, Dongduk Womens University). Retrieved December 28, 2017 from http://dcollection.dongduk.ac.kr/jsp/common/DcLoOrg Per.jsp?sltemld=000000105802

Park, M. J. (2018. 02. 26). Social Media Custom Collections. Asia Economy. Retrieved May 17, 2018 from http://view.asiae.co.kr/news/view.htm?idxno=2018022608523 816880

Park, R. M. (2018. 03. 22). Instagram, a rapid evolution into a shopping platform. Herald Economy. Retrieved May 17, 2018 from http://news.heraldcorp.com/view.php?ud=201803 22000080

Park, T. W., \& Lee, K. Y. (2014). An Integrated Model of Information Processing of eWOM in Social Network Service. Advertising Research, 26(2), 172-187. 
Petty, R. E., \& Cacioppo, J. T. (1996). Attitudes and persuasion: Classic and contemporary approaches. Boulder CO: Westview Press.

Pitt, L. F., Watson, R. T., \& Kavan, C. B. (1995). Service quality: A measure of information system effectiveness. MIS Quarterly, 19(2), 173-187.

Poddar, A., Donthu, N., \& Wei, Y. J. (2009). Website customer orientations, Web site quality, and purchase intentions: The role of Website personality. Journal Of Business Research, 62(4), 441-450.

Prybutok, V. R., Kappelnam, L. A., \& Myers, B. L. (1997). A comprehensive model for assessing the quality and productivity of the information systems function: Toward a theory for information systems assessment. Information Resources Management Journal, 101), 6-26.

Rha, J. Y. (2010). Consumers' Usage of Online Social Networks: Application of Use-Diffusion Model. Journal of Consumer Studies, 21(2), 443-472.

Seddon, P. (1997). A respecification and extension of the DeLone and McLean model of IS success. Information Systems Research, 8(3), 240-253.

Seddon, P., \& Kiew, M. Y. (1994). A partial test and development of the DeLone and McLean model of IS success. Proceeding of the Fifteenth International Conference on Information on Systems, 99-110

Seo, C. S. (2016). One person one business. Seoul, South Korea: Max Media.

Seo, D. U. (2015). The role of 'engagement in TV contents' as a mediating variable in the context of social viewing: Focused on uses and gratification theory. (Master dissertation, Yonsei University). Retrieved December 10, 2017 from http://library.yonsei.ac.kr/ search/detail/CAT000001748530

Shin, C. H., \& Ji, Y. H. (2014). The Study on the Influence of Social Media's Qualities and Purchasing Behavior Intention by Involvement of Hotel Accommodation Product. Korean Journal of Hospitality and Tourism, 23(4), 23-39.

Shin, D. Y. (2016). The Effects of SNS Users' Motivation and Behavior on SNS user satisfaction. (Master dissertation, Yonsei University). Retrieved December 10, 2017 from http://library.yonsei.ac.kr/search/detail/CAT 000001777379

Shin, H. J. (2017). Fashion information search and willingness to share information: Influence of SNS commitment and motives. (Doctorial dissertation, Hanyang University). Retrieved December 10, 2017 from https://lib.hanyang.ac.kr/\#/search/detail/1712891

Siekpe, J. (2005). An examination of the multidimensionality of flow construct in a computer-mediated environment. Journal of Electronic Commerce Research, 6(1), 31-43.

Sommer, L. (2011). The theory of planned behaviour and the impact of past behaviour. The International Business \& Economics Research Journal, 1011), 91-110.

Suh, S. E., \& Kim, M. J. (2014). Imaginary Ego-image and Fashion Styles represented in the Social Media Focusing on women's personal fashion blogs -. Journal of the Korean Society of Costume, 64(7), 128-142.

Suh, W. J., Won, W. Y., \& Hong, J. W. (2010). An Empirical Study on the Effects of SNS Website Quality Factors on the User Satisfaction, Intention of Continuous Use, and Intention of Words-of-Mouth. Journal of Industrial Innovation, 26(1), 99-132

Sung, H. J., \& Ko, J. Y. (2013). The Study of the Effects of On-line Social Network Service Differenceson Customer Satisfaction and Intention of Use:Focused on the Extended Technology Acceptance Model. Journal of Tourism Sciences, 37(2), 187-211.

Van Dyke, T. P., Kappelman, L. A., \& Prybutok, V. R. (1997). Measuring information systems service quality: concerns on the use of the SERVQUAL questionnaire. MIS Quarterly, 21(2), 195-208.

Woo, J. P. (2012). Concept and understanding of structural equation model. Seoul, South Korea: Hannarae Publishing Co.

YanShu, Yin. (2016). The influence of satisfaction for social media quality services on usage persistence. (Master dissertation, Cheongju University). Retrieved December 10, 2017 from http://library.cju.ac.kr/search/detail/CATTOT0000 00571120

Yu. S. H. (2016). Social media changes the future of the fashion industry. Fashion Seoul. Retrieved December 10, 2017 from http://www.fashionseoul.com/121362

Zeithaml, V. A., Berry, L. L., \& Parasuraman, A. (1996). The behavioral consequences of service quality. Journal of Marketing, 60(2), 31-46. 